Limnol. Rev. (2015) 15, 1: 3-14

DOI 10.2478/limre-2015-0001

\title{
Impact of curved shaped energy dissipaters downstream of head structures on both water energy dissipation and irrigation water quality
}

\author{
Mohamed A. Ashour ${ }^{1}$, Tarek Sayed ${ }^{2}$, Salah El-Attar ${ }^{1}$ \\ ${ }^{1,3}$ Department of Civil Engineering, Faculty of Engineering, Assiut University, 71515 Assiut, Egypt, \\ e-mail: mashour475275@yahoo.com (corresponding author) \\ ${ }^{2}$ Department of Civil Engineering, Faculty of Engineering, Assiut University, 71515 Assiut, Egypt, \\ e-mail: tareksayed1986@gmail.com
}

\begin{abstract}
Using energy dissipaters on the soled aprons downstream of head structures is the main technique for accelerating hydraulic jump formation and dissipating a great amount of the residual harmful kinetic energy occurring downstream of head structures. In this paper, an experimental study was conducted to investigate some untested shapes of curved dissipaters with different angles of curvature and arrangements from two points of view. The first is to examine its efficiency in dissipating the kinetic water energy. The second is to examine the most effective shape and arrangement obtained from the aforementioned step in enriching the flow with dissolved oxygen for enhancement of the irrigation water quality. The study was held in the irrigation and hydraulic laboratory of the Civil Department, Faculty of Engineering, Assiut University, using a movable bed tilting channel $20 \mathrm{~m}$ long, $30 \mathrm{~cm}$ wide, and $50 \mathrm{~cm}$ high, using 21 types of curved dissipaters with different arrangements. A total of 660 runs were carried out. Results were analysed, tabulated and graphically presented, and new formulas were introduced to estimate the energy dissipation ratio, as well as the DO concentrations. Results in general showed that the dissipater performance is more tangible in dissipating the residual energy when the curvature is in the opposite direction to that of the flow. Also, the energy loss ratio increases with an increase in curvature angle $(\theta)$, until it reaches $\left(\theta=120^{\circ}\right)$, then it decreases again. The study also showed that using three rows of dissipaters give nearly the same effect as using four rows, concerning both the relative energy dissipation and dissolved oxygen content. So, it is recommended to use three rows of the curved dissipater with the angle of curvature $\left(\theta=120^{\circ}\right)$ in the opposite direction to that of the flow to obtain the maximum percentage of water energy dissipation downstream of head structures, and maximum dissolved oxygen content too
\end{abstract}

Key words: energy dissipation, kinetic water energy, hydraulic jump, curved dissipater, water quality, dissolved oxygenKey words: energy dissipation, hydraulic jump, curved sill dissipater, water quality, dissolved oxygen.

\section{Introduction}

Energy dissipation. Flow over spillways or underneath gates has a tremendous amount of potential energy, which is converted into kinetic energy downstream of head structures. This energy must be dissipated shortly and safely as near as possible to the head structure to avoid its destructive effect. Using energy dissipaters on the soled apron downstream of head structures was the main technique for accelerating the hydraulic jump formation and dissipating a great amount of the residual harmful kinetic energy occurring downstream of head structures. So early on, many researchers investigated different types, shapes, and arrangements of such dissipaters to evaluate their efficiency in dissipating the water energy and accelerating the forming of the hydraulic jump, for example, Peterka (1958), El-Gawhary et al. (1986), Aziz et al. (1999), Alikhani et al. (2010), Bastawy (2013), Habib and Nasser (2013), and Tiwari et al. (2013). Many relations and equations for determining the energy dissipation percentage downstream of head structures have been developed, such as those developed by Rageh (1999), Wafai (2001a, 2001b), Negm et al. (2003), Habib (2012), Habib et al. (2012), and Shahmirzadi et al. (2012), which are reviewed in our previous work (Ashour et al. 2014). 
Irrigation water quality. Currently there is much emphasis on water quality and maintaining water quality parameters in our freshwater hydrosphere (rivers, lakes, and reservoirs). Dissolved oxygen (DO) concentration is one of the most widely cited parameters, since it is often used as a good indicator for the quality of water used by humans or serving as a habitat for aquatic flora and fauna. DO is typically measured and reported as concentrations using either mg DO per litre of water $\left(\mathrm{mg} \mathrm{dm}^{-3}\right)$ or percentage saturation as the units (Wilson 2013). Rule 64 of the Michigan Water Quality Standards (Part 4 of Act 451) (DEQ 2006) includes minimum concentrations of DO which must be met in surface waters of the state. The variability in DO in rivers is caused by the influences of many factors, and the major influences can be categorized as being either sources or sinks of DO in rivers (Cox 2003). The major sources of DO include reaeration from the atmosphere, enhanced aeration at weirs and other structures, photosynthetic oxygen production and the introduction of DO from other sources such as tributaries. The main causes of oxygen depletion, or sinks, are the oxidation of organic and other material, degassing of oxygen in supersaturated water, respiration by aquatic plants and the oxygen demand exerted by river bed sediments. Since the DO content is a significant indicator for the aeration of the water, enhancing the water DO content through aeration is extensively studied in the literature review. Gameson (1957) was the first to report on the aeration potential of weirs in rivers. Since then air entrainment and the aeration efficiency of hydraulic structures have been studied experimentally by a number of investigators, notably Van der Kroon and Schram (1969), Avery and Novak (1978), and Nakasone (1987), and more recently, Bayler and Bagatur (2006), Bayler et al. (2008), and Ozkan et al. (2009). Investigations have also been reported on the aeration performance of existing hydraulic structures and these are reviewed by Wilhelms et al. (1992). As for the studies done on the direct effect of hydraulic structures on DO concentrations, a study was carried out by El Baradei (2011). But this study investigated the effect of gates on the DO concentration. El Baradei (2013) studied the effect of broad crested trapezoidal weirs on the DO concentration at two different water depths. Results showed that installing the weir increased the values of the DO (comparing its upstream side with the downstream side) by an average of 5.3\% comparing all depths. Reviewing the literature review concerning the enhancement of the DO content proved that very limited research makes a link between the energy dissipation and the flow enrichment with the DO for improving the quality of water, such as research by Kucukali and Cokgor (2009), and Anandraj (2012), who confirmed the positive linear relationship between aeration efficiency and energy loss along the jump as follows:

$$
E_{20}=0.0024 \omega+0.0499 \text {. }
$$

To the best of our knowledge, there are no studies that have been done for linking the effect of the shape of the energy dissipaters downstream of head structures on the energy dissipation, and the gained quantity of DO which is reflected in improving the irrigation water quality as well. So, this paper is focused on the study of the untested shapes of curved dissipaters with different angles of curvature and arrangements from two points of view:

The first is to examine its efficiency in dissipating the kinetic water energy;

The second is to examine the most effective shape and arrangement obtained from the aforementioned step in enriching the flow with dissolved oxygen for the enhancement of the irrigation water quality.

\section{Methods}

Dimensional analysis. Referring to Fig.1, the following functional form for the dissipation of energy in a rectangular basin with curved sill dissipaters could be expressed as follows:

$$
\Delta E=\phi\left(\rho, \mu, g, D, y_{1}, y_{2}, L_{w}, L_{j} L_{s}, h, \theta, q\right) .
$$

Since $h_{s}$ and $L_{s}$ were kept constant throughout the experimental programme, they will be removed from Eq. 2. Also, the effect of viscosity is assumed to be of secondary importance in estimating the energy dissipation parameters as the flow is mainly gravitational, and therefore, the effect of the Reynolds number, $R_{e}$, can be ignored; then, these variables can be grouped into the following non-dimensional parameters by use of dimensional analysis:

$$
\frac{\Delta E}{y_{1}}=\phi\left(\frac{y_{2}}{y_{1}}, \frac{L_{j}}{y_{1}}, \frac{L_{w}}{y_{1}}, \theta, F_{\mathrm{el}}\right)
$$



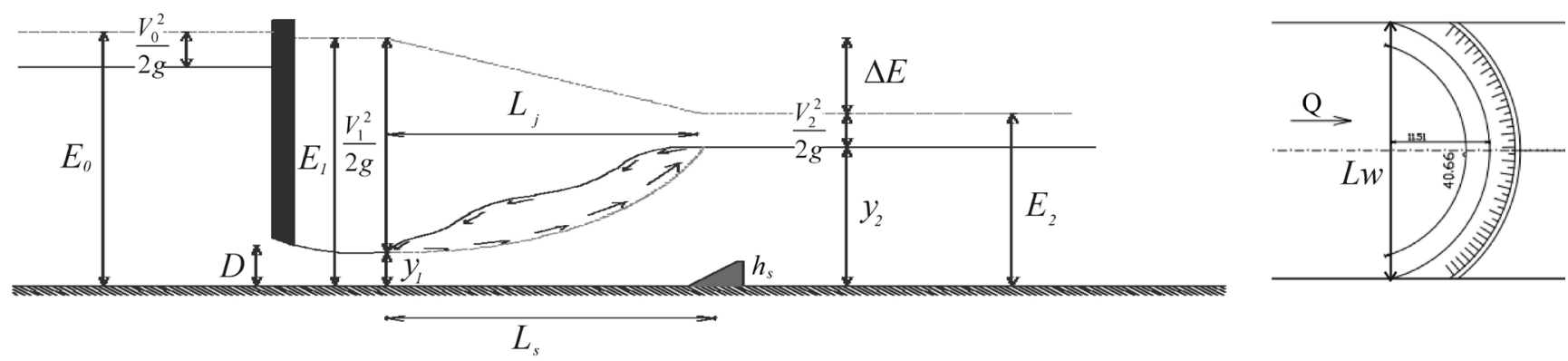

Fig. 1. Definition sketch for forced hydraulic jump with curved end sill

Experimental set-up. Experiments were performed in a recirculation, rectangular open tilting flume at the Irrigation and Hydraulic laboratory of the Civil Engineering Department at Assiut University, Egypt. As shown in Fig. 2, the flume is $17.50 \mathrm{~m}$ long, $0.30 \mathrm{~m}$ wide and $0.50 \mathrm{~m}$ deep with an adjustable slope. Measurements of water depth were recorded using an electrical point gauge mounted on an aluminium frame over the channel, so it could be moved longitudinally and transversely over the channel. The gauge was equipped with a vernier, readable to reach an accuracy of about $0.10 \mathrm{~mm}$. Measurements of the DO concentration were measured using a VWRbrand Dissolve Oxygen Meter Model 4000. A sluice gate made of aluminium was used as a heading-up structure and the tail gate was located at the end of the channel to control the downstream water depth.

Experimental approach. Twenty one different shapes of end sill were tested as energy dissipaters downstream of the sluice gate model. Detailed dimensions and arrangements of the tested energy dissipater models are shown in Table 1. These models were made of painted timber to be placed separately on the flume bed downstream of the sluice gate. 660 runs were conducted and were categorized into three sets of experiments. The first set of experimental runs was carried out on the downstream floor without energy dissipaters. This set included 30 runs and was considered as a reference in order to estimate the effect of using the tested energy dissipaters. The second set of experimental runs was carried out using twelve types of curved dissipaters having a curvature angle of 60 , $75,90,120,150$, and 180 degrees, in addition to the straight one as a reference. This set included 390 runs. The third set of experimental runs, was carried out using the most effective shape obtained from the aforementioned step as one continuous row or more, or as staggered separate dissipaters in one or more rows, to examine its efficiency in dissipating water energy, and at the same time its role in enriching the flow with oxygen through the great aeration of the flow within the dissipating energy distance downstream of the head structure. This set included 240 runs. In each test, six different discharges between 4.75 and $25.21 \mathrm{dm}^{3} \mathrm{~s}^{-1}$ were used with five gate openings between 20 and $50 \mathrm{~mm}$; the position of the models was fixed so that

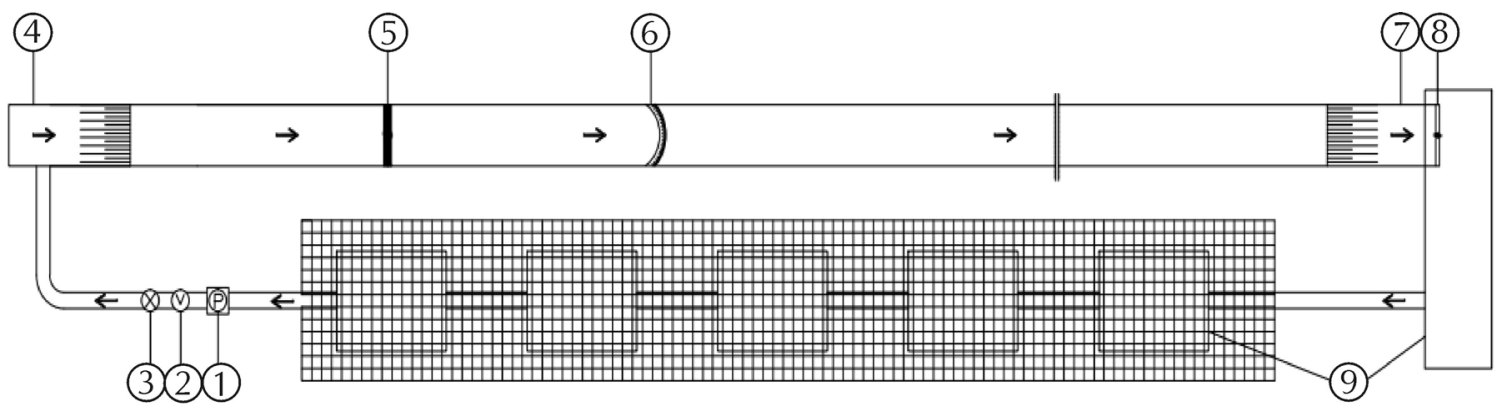

1 - Pump, 2 - Valve, 3 - Orifice meter, 4 - Approach basin, 5 - Sluice gate, 6 - End sill, 7 - Downstream ramp, 8 -Tail gate, 9 - Collecting tanks

Fig. 2. Experimental Set-up 
Table 1. The tested configurations of curved sill dissipaters

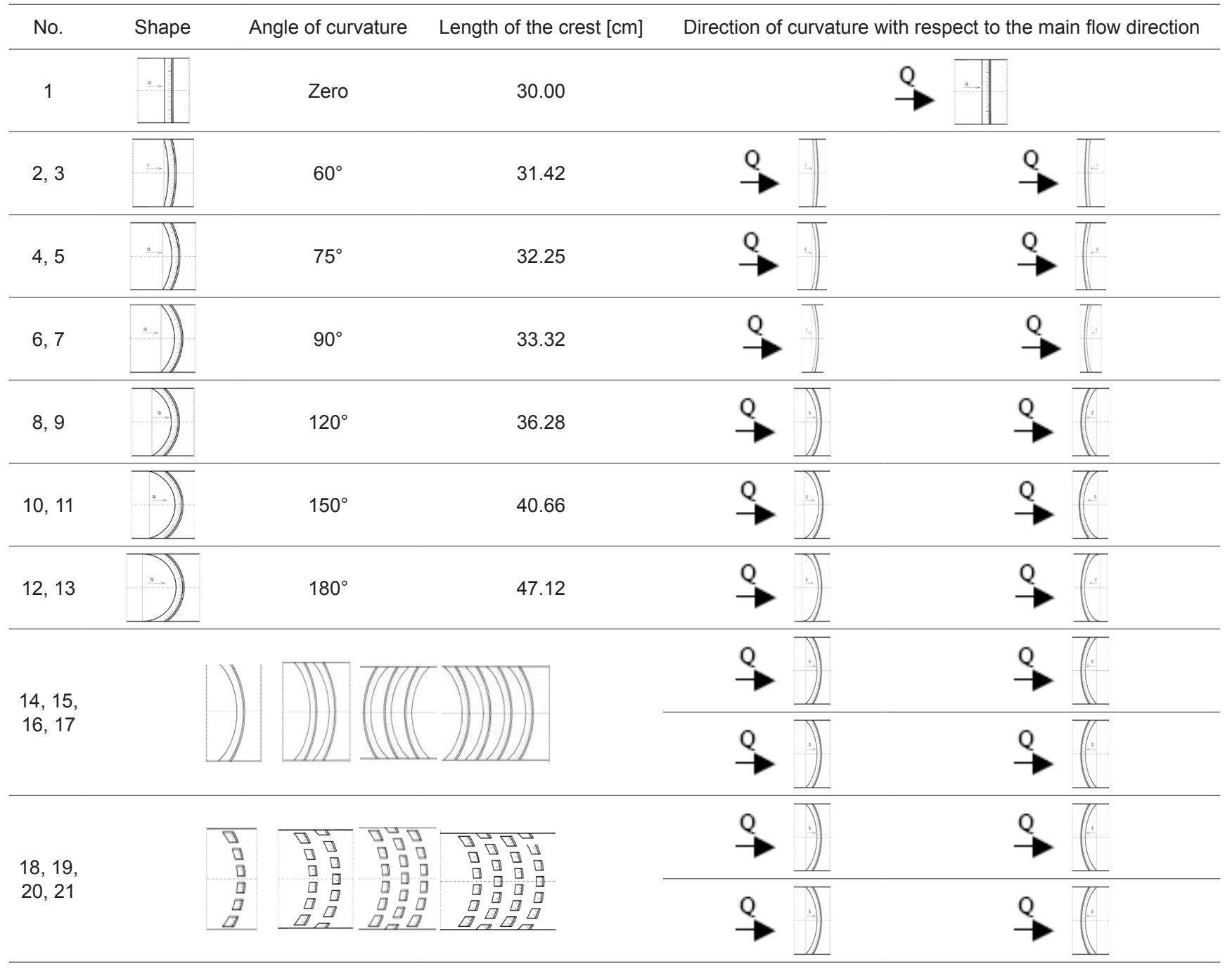

$\left(L_{s} / b=5.83\right)$, and the height of the models was fixed so that $\left(h_{s} / b=0.11\right)$ as recommended by Wafaie (2001a, 2001b).

Experimental procedures. Runs were started with the models fixed separately on the flume bed downstream of the sluice gate. The storage tank was filled with low dissolved oxygen content water (drainage water), to obtain tangible measured values of DO before and after using the tested dissipaters. The intake valve of the feeding pipeline was opened slowly to give a definite value of discharge through adjusting both the intake valve and the water manometer reading. The downstream tail gate was adjusted to obtain free flow conditions, after a period of about 20 to 30 minutes. The measurements of the water depths $\left(y_{0}, y_{1}\right.$, $y_{2}$ ) were made in three longitudinal axes of the flume at $b / 4, b / 2$, and $3 b / 4$, in which $b$ is the flume width, and then the average values were determined. The jump length was measured then by the use of the horizontal scale. During the experiments, DO measurements upstream and downstream of the curved dissipater were taken using a calibrated portable VWRbrand Dissolve Oxygen Meter Model 4000 at the locations identified in Fig. 3; at every position three measurements were taken, near to the water surface, near to the bed of the flume and at the mid-water depth. The DO meter was calibrated daily prior to use, by the air calibration method. Calibration procedures followed those recommended by the manufacturer. The calibration was performed in humid air under ambient conditions. 


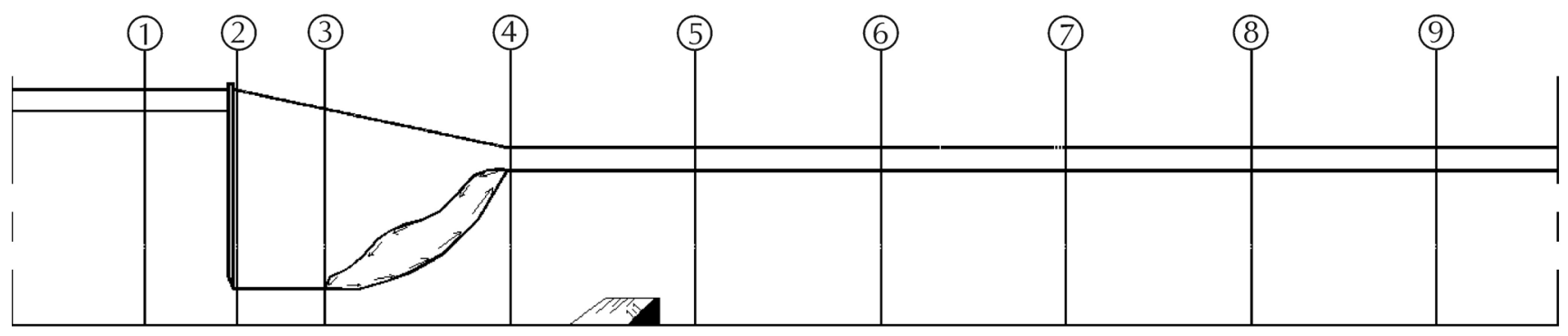

Fig. 3. Locations of dissolved oxygen measurements points

\section{Results and analysis}

Energy dissipation. Experimental results were expressed in dimensionless forms and represented graphically to study the efficiency of the used sill dissipaters in dissipating the water energy and accelerating the forming of the hydraulic jump. Relationships between the values of relative energy loss $\left(\Delta E / E_{1}\right)$, and the inflow Froude Number $\left(F_{e 1}\right)$ for sill dissipaters are illustrated in Fig. 4, (as an example). From this figure, it is clear that increasing the values of $F_{e l}$ increases the value of $\Delta E / E_{1}$ for all sill dissipaters under study. For further increases in $F_{e l}$, the differences of $\Delta E / E_{1}$ increase for different dissipater curvature. For the same angle of curvature, the dissipater performance is more tangible in dissipating the residual energy when the curvature is in the opposite direction to that of the flow. Table 2 shows that the amount of increase in $\Delta E$ / $E_{1}$ for curved dissipaters is more than that obtained with the straight dissipater, and also without using any dissipaters.

Relationships between the values of relative energy loss $\left(\Delta E / E_{1}\right)$ and the angle of dissipater curvature for the curved sill dissipaters under study are illustrated in Fig. 5 as an example. From this figure, it is clear that the $\Delta E / E_{1}$ increases with the increase in the angle of curvature $(\theta)$, until it reaches $\theta=120^{\circ}$, then it decreases. For all angles of dissipater curvature $(\theta)$,

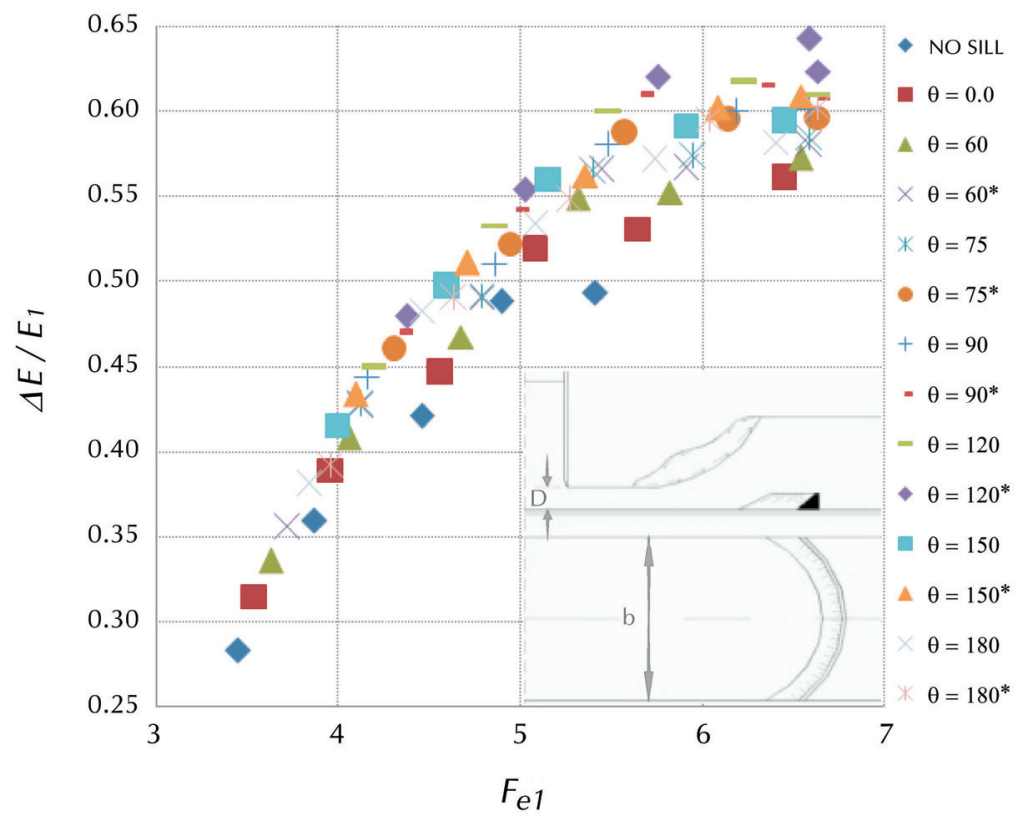

Fig. 4. Relationship between relative energy loss and Froude Number for all sill dissipaters under study, curvature at $(D / b=1 / 10)$ 
Table 2. Comparison between the measured relative energy dissipation for the studied models

\begin{tabular}{ccccc}
\hline Angle of curvature & In the direction of flow & $\begin{array}{c}\text { In the opposite direction } \\
\text { to flow }\end{array}$ & In the direction of flow & $\begin{array}{c}\text { In the opposite direction } \\
\text { to flow }\end{array}$ \\
\hline $60^{\circ}$ & $0.60-11.40$ & $0.70-13.00$ & $3.30-26.70$ & $5.00-28.90$ \\
\hline $75^{\circ}$ & $0.43-14.90$ & $2.55-18.30$ & $3.50-27.40$ & $5.20-32.10$ \\
\hline $90^{\circ}$ & $2.30-20.10$ & $4.00-24.15$ & $5.00-33.40$ & $6.70-36.30$ \\
\hline $120^{\circ}$ & $3.50-24.70$ & $5.70-30.40$ & $9.20-36.55$ & $13.0-42.55$ \\
\hline $150^{\circ}$ & $0.42-16.11$ & $3.16-19.30$ & $5.16-30.60$ & $9.00-34.10$ \\
\hline $180^{\circ}$ & $0.17-10.90$ & $0.11-13.60$ & $2.50-24.70$ & $5.05-27.75$ \\
\hline
\end{tabular}

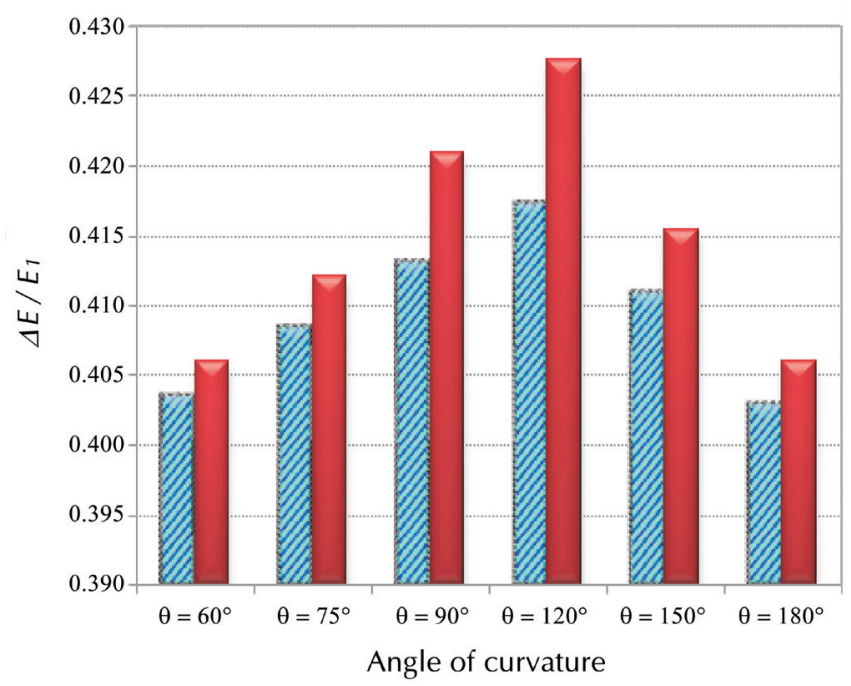

Fig. 5. Relationship between relative energy loss and angle of dissipater curvature for all curved sill dissipaters under study at $F_{e 1}=$ 6.0 (blue bars) and $F_{e 1}=6.0$ (red bars)

the $\Delta E / E_{1}$ increases with the increase in the $F_{e 1}$. Also, it is clear that the difference in relative energy loss has a maximum value at $F_{e 1}=4.0$, while at $F_{e 1}=6.0$, the difference in relative energy loss is minimum. In addition, the results showed that the sill dissipater models with angles of curvature in the opposite direction to that of the flow are better than those with the angles of curvature in the same direction as the flow. The $\Delta E$ / $E_{1}$ for sill dissipater $\left(\theta=120^{\circ}\right)$ is larger than the $\Delta E / E_{1}$ for all other dissipaters with other values of angle of curvature $(\theta)$.

Figure 6 shows the relation between the $\Delta E / E_{1}$ and the angle of curvature for the curved sill dissipaters under study with angles of curvature in the opposite direction to that of the flow at $(D / b=1 / 7.5)$ for example. From this figure, it is clear that increasing the angle of curvature $(\theta)$ increases the $\Delta E / E_{1}$ until $\theta=120^{\circ}$ then, the $\Delta E / E_{1}$ decreases for different discharges. From this figure also, it is clear that increasing the values of $Q$ increases the value of $\Delta E / E_{1}$ for all sill

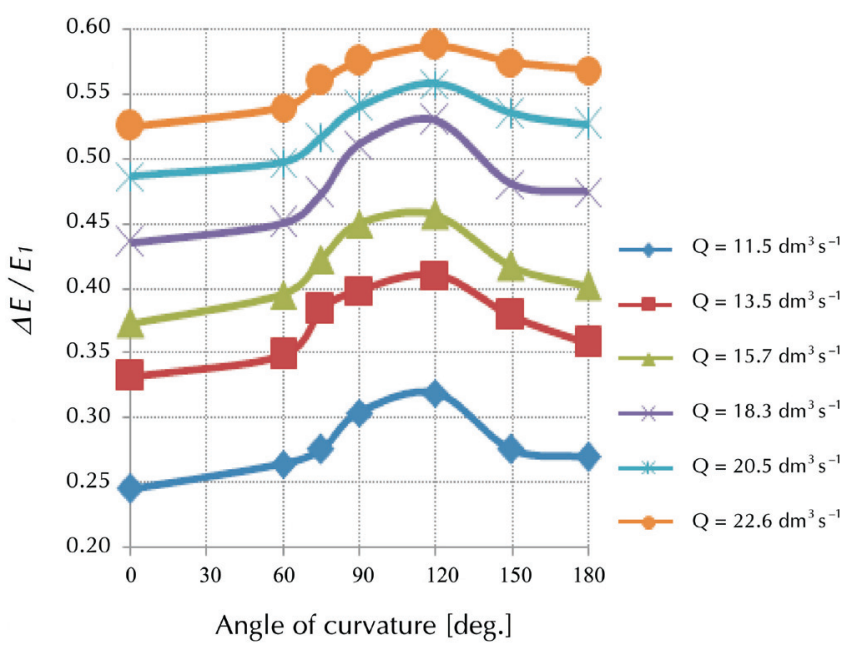

Fig. 6. Relationship between Relative energy loss and angle of dissipater curvature for different examined discharges at $(D / b=$ $1 / 7.5)$

dissipaters under study; for further increases in $Q$, the differences in $\Delta E / E_{1}$ for different models decreases.

Based on the experimental data and using the simple and multiple linear regression analysis, the best equation predicting the relative energy loss in the case of curved sill dissipaters can be put in the following form:

$$
\frac{\Delta E}{E_{1}}=A \ln \left(F_{e 1}\right)-B
$$

The values of the coefficients $A$ and $B$ are listed in Table 3 . The coefficients $(A, B)$ are clearly proved to be dependent on the angle of curvature. Figure 7 shows a comparison between the measured relative energy loss $\left(\Delta E / E_{1}\right)$ and the calculated one using Eq. 4. It may be noticed that the predicted data agree well with the measured data.

Table 4 introduces a comparison between the results of the present study and the most popular 
Table 3. Values of coefficients $A$ and $B$ given in Equation 4

\begin{tabular}{|c|c|c|c|c|c|c|c|}
\hline $180^{\circ}$ & $150^{\circ}$ & $120^{\circ}$ & $90^{\circ}$ & $75^{\circ}$ & $60^{\circ}$ & $0^{\circ}$ & Angle of curvature \\
\hline 0.4377 & 0.4453 & 0.4389 & 0.4464 & 0.4410 & 0.4392 & 0.4267 & Coefficient $A$ \\
\hline 0.2028 & 0.2050 & 0.1840 & 0.2024 & 0.2028 & 0.2079 & 0.2015 & Coefficient $B$ \\
\hline
\end{tabular}

Table 4. The most popular investigated methods for water energy dissipation D.S. of head structures with comparative analysis of its efficiency in dissipating the water kinetic energy with the results of the present study

\begin{tabular}{|c|c|c|c|c|c|}
\hline References & Equation & Definition sketch & $\begin{array}{c}\text { Shapes } \\
\text { of energy } \\
\text { dissipaters }\end{array}$ & $\begin{array}{l}\text { Computed } \\
\text { energy } \\
\text { dissipation }\end{array}$ & $\begin{array}{l}\text { Energy } \\
\text { dissipation } \\
\text { efficiency }\end{array}$ \\
\hline Rageh (1999) & $\Delta E / E_{1}=1-\left(\frac{F_{e_{1}}+2 r_{o} y_{o}}{r_{o} y_{o}\left(F_{e_{1}}+2\right)}\right)$ & & & $\begin{array}{l}\left(\Delta E / E_{l}\right)_{h s / y l=0}=0.651 \\
\left(\Delta E / E_{l}\right)_{h s y l=2}=0.673\end{array}$ & $3.50 \%$ \\
\hline Wafaie (2001a) & $\Delta E / E_{1}=\left(A_{E} \times F_{e_{1}}^{2}\right)+\left(B_{E} \times F_{e_{1}}\right)+C_{E}$ & & & $\begin{array}{l}\left(\Delta E / E_{l}\right)_{h s / y l=0}=0.548 \\
\left(\Delta E / E_{l}\right)_{h s y l=2}=0.657\end{array}$ & $19.84 \%$ \\
\hline Habib et al. (2003) & $\Delta E / E_{1}=\frac{r_{0}^{2} d_{o}^{2}\left(2+F_{e_{1}}^{2}-2 d_{o}\right)-F_{e_{1}}^{2}}{r_{0}^{2} d_{o}^{2}\left(2+F_{e_{1}}^{2}\right)}$ & & & $\begin{array}{l}\left(\Delta E / E_{l}\right)_{h s / y l=0}=0.599 \\
\left(\Delta E / E_{l}\right)_{h s y l=2}=0.623\end{array}$ & $4.10 \%$ \\
\hline Negm et al. (2003) & $\Delta E / E_{1}=-0.973-0.153 F_{e_{1}}+1.031 F_{e_{1}}^{2}+0.006 h_{s} / y_{1}$ & & & $\begin{array}{l}\left(\Delta E / E_{l}\right)_{h s / y l=0}=0.634 \\
\left(\Delta E / E_{l}\right)_{h s y l=2}=0.646\end{array}$ & $1.90 \%$ \\
\hline Habib (2012) & $\Delta E / E_{1}=1-\left[\frac{D_{0}^{2}\left(Z+D_{o}\right)\left(e+2 C^{* *}\right)^{2}+0.5 F_{e_{1}}^{2}}{D_{0}^{2}\left(1+0.5 F_{e_{1}}^{2}\right)\left(e+2 C^{* *}\right)^{2}}\right]$ & & & $\begin{array}{l}\left(\Delta E / E_{l}\right)_{h s y l=0}=0.581 \\
\left(\Delta E / E_{l}\right)_{h s y l=2}=0.756\end{array}$ & $30.12 \%$ \\
\hline Habib et al. (2012) & $\Delta E / E_{1}=1-\frac{\left[y_{r}+\frac{0.5 F_{e_{e}}^{2}\left(b / y_{1}\right)^{2}}{\left(b / y_{1}\right)^{2} y_{r}^{2}+0.5\left(b / y_{1}\right)^{3}+0.0625 y_{r}^{4}}\right]}{\left(1+0.5 F_{e_{1}}^{2}\right)}$ & & & $\begin{array}{l}\left(\Delta E / E_{l}\right)_{h s / y l=0}=0.474 \\
\left(\Delta E / E_{l}\right)_{h s / y l=2}=0.538\end{array}$ & $13.45 \%$ \\
\hline Shahmirzadi et al. (2012) & $\Delta E / E_{1}=\left[\left(\frac{V_{0}^{2}}{2 g}+y_{3}\right)-\left(\frac{V_{5}^{2}}{2 g}+y_{5}\right)\right] /\left(\frac{V_{0}^{2}}{2 g}+y_{3}\right)$ & & & $\begin{array}{l}\left(\Delta E / E_{l}\right)_{h s y l=0}=0.880 \\
\left(\Delta E / E_{1}\right)_{h s y l=2}=0.903\end{array}$ & $2.75 \%$ \\
\hline The present study & $\Delta E / E_{1}=A \ln \left(F_{e_{1}}\right)-B$ & & & $\begin{array}{l}\left(\Delta E / E_{l}\right)_{h s / y l=0}=0.444 \\
\left(\Delta E / E_{l}\right)_{h s / y l=2}=0.607\end{array}$ & $13.0-42.5 \%$ \\
\hline
\end{tabular}

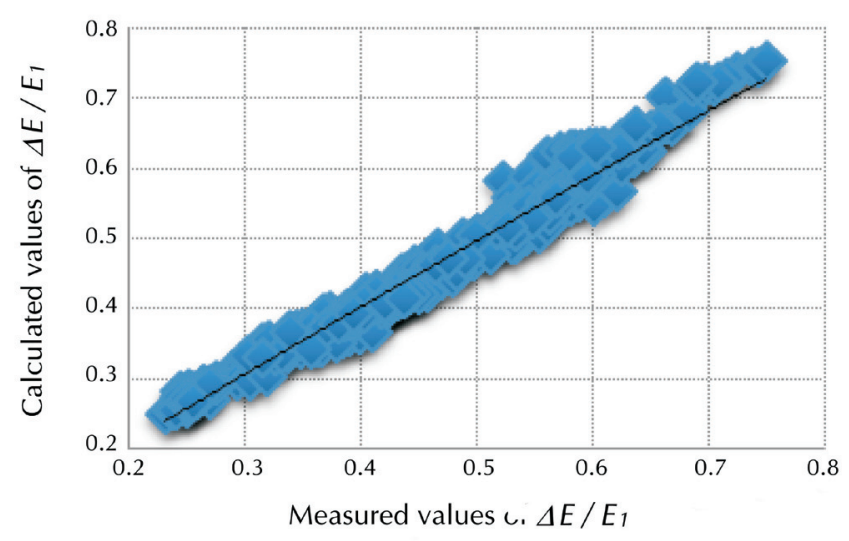

Fig. 7. Comparison between measured and calculated values of $\Delta E / E_{1}$ by using Equation 4 methods investigated by other authors and their predicted relations and equations for determining the energy dissipation percentage. For the purposes of comparison, the last column of Table 4 presents the calculated percentage value of the energy dissipated according to each of the tabulated author's equations. From this table, it is clear that the present study introduced a new water energy dissipater for more efficient energy dissipation, which can increase the dissipating water energy by about $42.55 \%$ compared with that which may be obtained without using any dissipaters.

The effect of repeating rows on the efficiency of energy dissipation. The results of testing the effect of a number of rows of our recommended curved dissipat- 
ers $\left(\theta=120^{\circ}\right.$, in the opposite direction to that of the flow) rows downstream of head structures are given in Fig. 8, from which it is clear that, for all tested numbers of rows, increasing $F_{e l}$ values increases the value of $\Delta E /$ $E_{1}$. While further increases in $F_{e l}$ decreases the $\Delta E / E_{1}$ for all tested numbers of dissipater rows. Table 5 shows the increase in the relative energy loss for the tested number of rows with respect to that obtained using the regular straight dissipater. Also, the following results are clear:

- For all studied numbers of rows, the staggered separate dissipaters are more effective than the continuous one;

- More than three rows gives intangible values of the gained energy dissipation.

Figure 9 shows the relation between the relative energy loss $\left(\Delta E / E_{1}\right)$ and the number of our introduced new dissipater $\left(\theta=120^{\circ}\right.$ in the opposite direction to that of the flow) for a different gate opening as an example. From which it is clear that the $\Delta E / E_{1}$ increases with an increasing number of rows, until three rows, after which more rows did not give any increase in the relative energy loss. Also, using three rows of dissipaters gives nearly the same effect as using four rows in increasing the relative energy dissipation. So, it is recommended to use three rows of the curved dissipater with an angle of curvature $\theta=120^{\circ}$ in the opposite direction to that of the flow to obtain the maximum percentage of water energy dissipation downstream of head structures.

The following equation is introduced for estimating the relative energy loss values downstream of head structures as a function of the Froude number, and the number of dissipater rows:

$$
\frac{\Delta E}{E_{1}}=0.09289-0.00113 N+0.08306 F_{\text {el }} \text {. }
$$

Equation 5 was valid for the flow conditions used with correlation $\mathrm{R}^{2}$ equal to 0.921 .

Irrigation water quality. Experimental results were represented graphically to study the effect of the number of rows of our recommended curved dissipater $\left(\theta=120^{\circ}\right.$, in the opposite direction to that of the

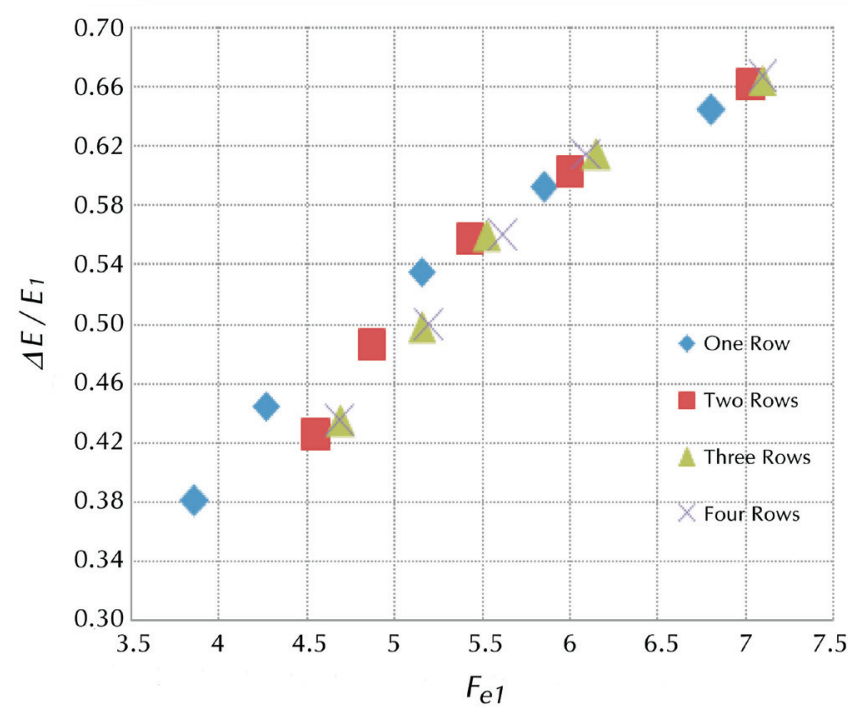

Fig. 8. Relationship between relative energy loss and Froude Number for all study row numbers at $(D / b=1 / 12)$

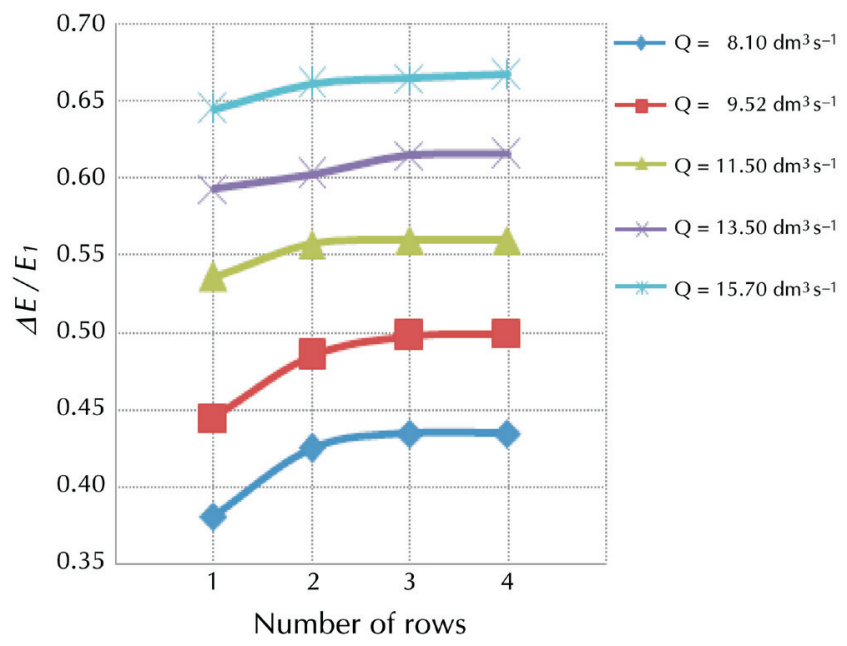

Fig. 9. Relationship between relative energy loss and number of rows for different examined discharges at $(D / b=1 / 12)$

flow) in the enrichment of the flow with DO along the stilling basin downstream of head structures. It should be noted that the experimental study was done by using one, two, three and four rows. Fig. 10 shows the DO concentration observed during experiments for the case of using three rows as a function of hori-

Table 5. Comparison of the measurable relative energy dissipation for the different number of rows

\begin{tabular}{|c|c|c|c|c|c|c|c|c|}
\hline \multirow[b]{2}{*}{ Number of rows } & \multicolumn{2}{|c|}{ One row } & \multicolumn{2}{|c|}{ Two rows } & \multicolumn{2}{|c|}{ Three rows } & \multicolumn{2}{|c|}{ Four rows } \\
\hline & Continuous & $\begin{array}{l}\text { Staggered } \\
\text { separate }\end{array}$ & Continuous & $\begin{array}{l}\text { Staggered } \\
\text { separate }\end{array}$ & Continuous & $\begin{array}{l}\text { Staggered } \\
\text { separate }\end{array}$ & Continuous & $\begin{array}{l}\text { Staggered } \\
\text { separate }\end{array}$ \\
\hline $\begin{array}{l}\text { The amount of increase in } \\
\text { the relative energy loss }\end{array}$ & $5.70-30.40$ & $6.70-31.15$ & $8.40-33.30$ & $8.75-34.20$ & $9.00-34.90$ & $9.30-36.00$ & $9.30-35.15$ & $9.60-33.30$ \\
\hline
\end{tabular}




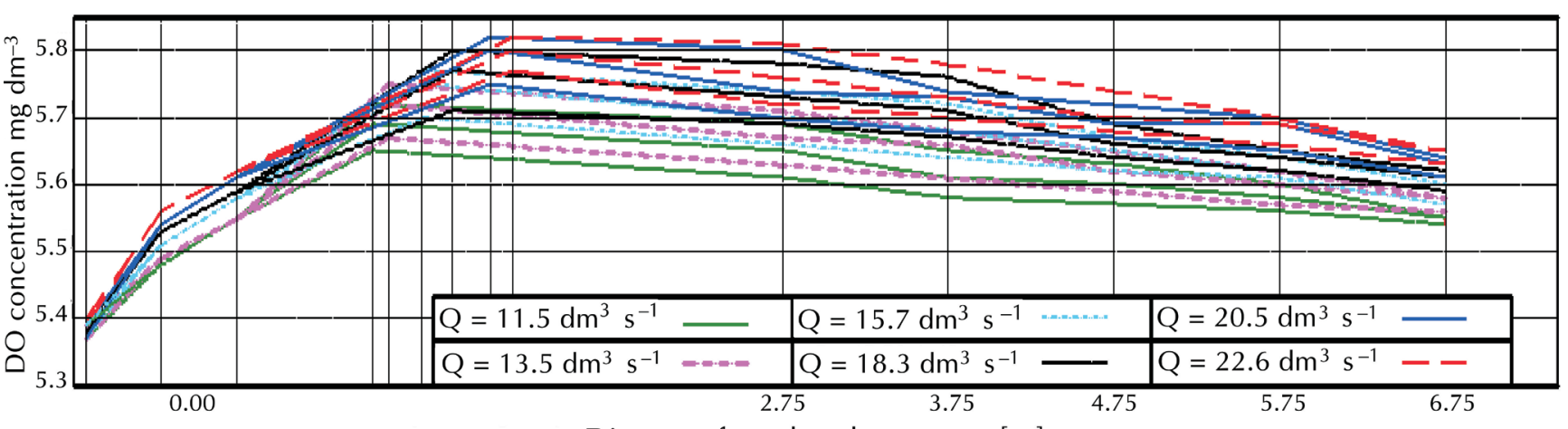

Distance from head structure $[\mathrm{m}]$

Fig. 10. Variation in dissolved oxygen concentration downstream of the head structure using three rows of our recommended curved dissipater $\left(\theta=120^{\circ}\right.$, in the opposite direction to that of the flow) for different discharges at $(D / b=1 / 10)$

zontal distance downstream of the head structure for different discharges (as an example). From this figure, it is clear that DO concentrations increase with the increase in the number of rows up to three rows. While a further increase in the number of rows decreases the differences between the values of DO concentrations for two sequent positions. For the same value of discharge, using four rows gives the best performance in increasing the DO concentrations compared with that obtained with one or two rows. The results, using one, two, three and four rows, are given in Table 6. From that table the following findings are clear:
- for all studied numbers of rows, the staggered separate dissipaters are more effective than the continuous one,

- using three rows of dissipaters gives nearly the same effect as using four rows in increasing the DO concentrations. So, it is not recommended to use more than three rows of energy dissipaters.

The results confirmed that the effect of our recommended curved dissipater $\left(\theta=120^{\circ}\right.$, in the opposite direction to that of the flow) is tangible in DO concentrations downstream of the head structure as shown in Fig. 11 (as an example). It worth mentioning that the

Table 6. Comparison of the measurable DO concentrations for the different number of rows

\begin{tabular}{|c|c|c|c|c|c|c|c|c|}
\hline \multirow[b]{2}{*}{ Number of rows } & \multicolumn{2}{|c|}{ One row } & \multicolumn{2}{|c|}{ Two rows } & \multicolumn{2}{|c|}{ Three rows } & \multicolumn{2}{|c|}{ Four rows } \\
\hline & Continuous & $\begin{array}{l}\text { Staggered } \\
\text { separate }\end{array}$ & Continuous & $\begin{array}{l}\text { Staggered } \\
\text { separate }\end{array}$ & Continuous & $\begin{array}{l}\text { Staggered } \\
\text { separate }\end{array}$ & Continuous & $\begin{array}{l}\text { Staggered } \\
\text { separate }\end{array}$ \\
\hline $\begin{array}{c}\text { Percentage of DO } \\
\text { concentration using different } \\
\text { numbers of rows }\end{array}$ & $1.10-4.70$ & $1.60-5.80$ & $1.80-5.10$ & $2.20-6.30$ & $2.20-5.60$ & $2.20-6.70$ & $2.40-5.90$ & $2.50-7.20$ \\
\hline
\end{tabular}

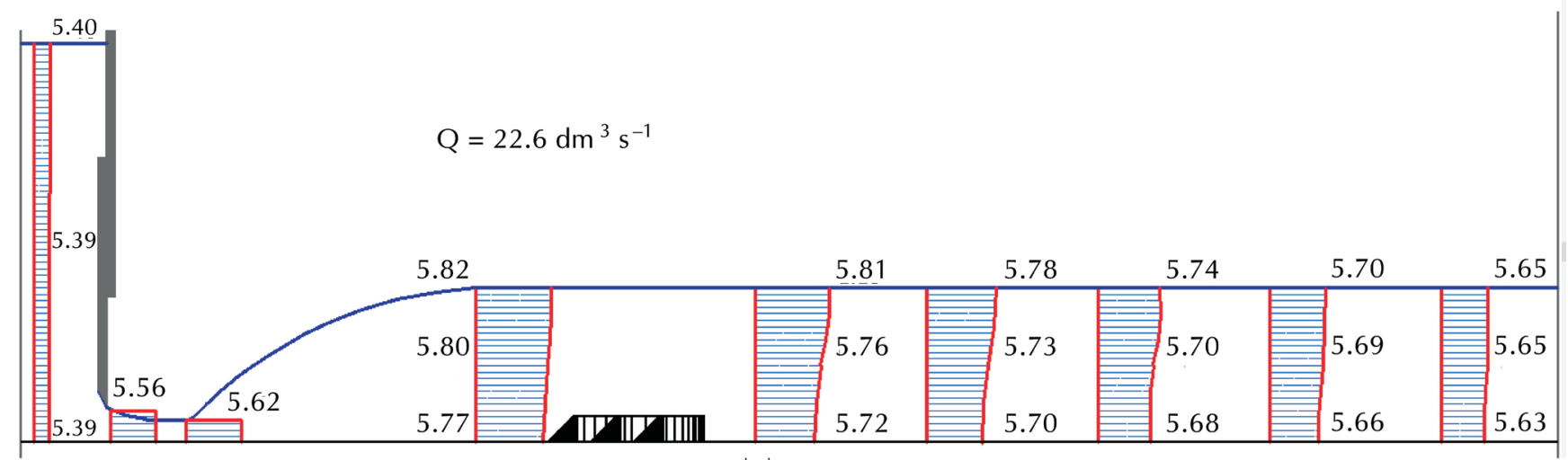

Fig. 11. Variation in dissolved oxygen concentration with horizontal distance downstream of the head structure and vertical depths of water using three rows of our recommended curved dissipater $\left(\theta=120^{\circ}\right.$, in the opposite direction to that of the flow $)$ at discharge $\mathrm{Q}=$ $22.6 \mathrm{dm}^{3} \mathrm{~s}^{-1}$ 
DO concentrations reach their maximum value at the end of the hydraulic jump formed downstream of the head structure, due to the huge aeration through the hydraulic jump and start decreasing in the longitudinal direction of flow until they reach the same values recorded. Using our recommended new curved dissipater in three rows behind the hydraulic jump increases the DO content with tangible values as shown in Fig. 11.

To know the distribution of the DO concentrations in the vertical direction, the measurements were taken at three points: the first near the bottom, the second in the middle of the water depth, and the last near the water surface. The recorded measurements showed that the DO concentrations have the minimum value near the bottom and increase slightly to reach their maximum value near the water surface.

To estimate the DO concentration downstream of head structures using our recommended dissipater $\left(\theta=120^{\circ}\right.$, in the opposite direction to that of the flow) as a function of the horizontal measuring distances from the head structures, and the measuring point along the water depth, we can use the following equation:

$$
\log (\mathrm{DO})=1.1949 \log (X)+0.0073 \log (Y)-0.2057 X+0.8778 .
$$

Equation 6 was valid for the flow conditions used with correlation $\mathrm{R}^{2}$ equal to 0.99 .

\section{Conclusions}

1. The following main technical points were concluded from the study:

2. Introducing a new water energy dissipater for more efficient energy dissipating improves the irrigation water quality at the same time by reaching the flow with dissolved oxygen too.

3. Curved dissipaters are more efficient in dissipating the water residual kinetic energy downstream of head structures than straight dissipaters.

4. The most efficient angle of curvature of dissipaters is 120 degrees.

5. Curvature of dissipaters in the opposite direction to that of the flow increases the efficiency of dissipating the energy by about $8.0 \%$ compared with that obtained with the curvature in the same direction as the flow.

6. Staggered discontinuous rows of the above-mentioned dissipaters can increase the dissipating water energy by about $7.0 \%$ compared with that which may be obtained using continuous rows of dissipaters.
7. For maximum percentage of water energy dissipation, and maximum dissolved oxygen content in the flow, it is recommended to use four rows of the above-mentioned introduced new dissipater in the staggered manner.

8. The following new simple practical equation is introduced for estimating the percentage of dissipating water energy downstream of head structures as a function of the Froude number, and the number of rows of dissipaters used (Eq. 5):

$$
\frac{\Delta E}{E_{1}}=0.09289-0.00113 N+0.08306 F_{e l}
$$

9. For estimating the percentage of dissolved oxygen gained downstream of head structures using the above-mentioned new dissipaters, as a function of the horizontal measuring distances from the head structures, and the measuring point along the water depth, the following equation was introduced (Eq. 6):

$$
\log (\mathrm{DO})=1.1949 \log (X)+0.0073 \log (Y)-0.2057 X+0.8778
$$




\section{Nomenclature}

\begin{tabular}{|c|c|}
\hline \multicolumn{2}{|c|}{ The following symbols are used in this paper: } \\
\hline$B$ & - width of the flume; \\
\hline $\bar{D}$ & - gate opening; \\
\hline$\overline{D O}$ & - dissolved oxygen; \\
\hline$E_{0}$ & - total flow of energy upstream of the sluice gate; \\
\hline$\overline{E_{1}}$ & - total flow of energy upstream of the jump; \\
\hline$E_{2}$ & - total flow of energy downstream of the jump; \\
\hline$\overline{\Delta E}$ & - energy loss; \\
\hline$F_{e l}$ & - Froude number upstream of the jump; \\
\hline$L_{B}$ & - length of stilling basin; \\
\hline$L_{j}$ & - length of jump; \\
\hline$L_{s}$ & - position of end sill from the gate; \\
\hline$L_{w}$ & - length of the crest; \\
\hline$R_{e l}$ & - Reynolds number upstream of the jump; \\
\hline$S_{0}$ & - bed slope of the channel; \\
\hline$V_{0}$ & - average velocity upstream of the sluice gate; \\
\hline$V_{1}$ & - average velocity at the initial depth; \\
\hline$V_{2}$ & - average velocity at the sequent depth; \\
\hline$b$ & - contracted width of the channel \\
\hline $\bar{g}$ & - gravitational acceleration; \\
\hline$h_{s}$ & - height of the end sill; \\
\hline$q$ & - discharge per unit width of the flume; \\
\hline$r_{0}$ & - ratio of $r_{2}$ to $r_{1}$ \\
\hline$r_{1}$ & - radius at the beginning of the jump; \\
\hline$r_{2}$ & - radius at the end of the jump; \\
\hline$\overline{y_{1}}$ & - initial depth of jump; \\
\hline$\overline{y_{2}}$ & - sequent depth of jump; \\
\hline$\overline{y_{c}}$ & - sequent depth of jump; \\
\hline $\bar{z}$ & - height of drop; \\
\hline$\theta$ & - end sill angle of curvature \\
\hline$\mu$ & - dynamic viscosity of the water; \\
\hline$\rho$ & - density of the water. \\
\hline
\end{tabular}

\section{References}

Anandraj A., 2012, Investigational study on self aeration characteristic of hydraulic jump, IOSR J. Mech. Civil Eng. (IOSR-JMCE) 4(2): 27-31.

Alikhani A., Behrozi-Rad R., Fathi-Moghadam M., 2010, Hydraulic jump in stilling basin with vertical end sill, Int. J. Phys. Sci. (IJPS) 5(1): 25-29.

Ashour M.A, Tarek S.A., Attar S., 2014, A new water energy dissipater for efficient energy dissipation and enriching the flow with dissolved oxygen content, Limnol. Rev. 14(1):3-11.

Avery S., Novak P, 1978, Oxygen transfer at hydraulic structures, J. Hydraul. Eng. 104(11): 1521-1540.

Aziz F.E., Al-Baidban F.J.H., Abdul Halim G., 1999, Dissipation of hydraulic energy by curved baffle blocks, Pertanika J. Sci. Technol. 7(1): 69-77.
Baylar A., Bagatur T., 2006, Experimental studies on air entrainment and oxygen content downstream of sharpcrested weirs, Water Environ. J. 20(4): 210-216.

Baylar A., Hanbay D., Ozpolat E., 2008, An expert system for predicting aeration performance of weirs by using ANFIS, Expert Syst. Appli. 35(3): 1214-1222.

Bestawy A., 2013, New shapes of baffle piers used in stilling basins as energy dissipators, Asian Trans. Eng. (ATE) 3(1): 1-7.

Cox B.A., 2003, A review of dissolved oxygen modeling techniques for lowland rivers, Sci. Total Environ. 314316: 303-334.

[DEQ] Department of Environmental Quality (State of Michigan), 2006, Part 4. Water Quality Standards [of Part 31, Water Resources Protection, of Act 451 of 1994] (Filed with the Secretary of State on January 13, 2006), Lansing, pp. 62. Retreived from http://www.michigan.gov/ documents/deq/wrd-swas-part4rules_492815_7.pdf

El Baradei S.A., 2011, Effect of free hydraulic jump on dissolved oxygen concentrations in water at different vertical control gate openings, ICASTOR Journal of Engineering 14(3): 281-291.

El Baradei S.A., 2013, Saving on energy of and determining the best location of water treatment plant along rivers depending on the effect of broad crested weir on dissolved oxygen concentrations in water, J. Clean Energy Technol. 1(3): 202-205.

El-Gawhary E.L., Soliman M.A., Hamed M.E., Zaghlor Y., 1986, Characteristics of flow near concave obstacles, Civil Engineering Research Magazine (CERM), A1-Azhar University $8(1)$

Gameson A., 1957, Weirs and aeration of rivers, J. Inst. Water Eng. 11(5): 477-490.

Habib A.A., 2012, Study of free flow below vertical sluice gate with positive step in redial stilling basin, Egypt. Int. J. Eng. Sci. Technology 15(1).

Habib A.A., Abdel-Azim M.A, Abd-Allh Y.M., Saleh Y.K., 2012, Estimation of hydraulic jump characteristics in stilling basin with guide walls, J. Eng. Sci. (JES) Assiut University, 40(6):1599-1609.

Habib A.A., Nassar M.A., 2013, Characteristics of flow and scour under the effect of curved steel roughness elements, Egypt. Int. J. Eng. Sci. Technol. (EIJEST) 16(3).

Kucukali S., Cokgor S., 2009, Energy concept for predicting hydraulic jump aeration efficiency, J. Environ. Eng. 135(2): 105-107.

Nakasone H., 1987, Study of aeration at weirs and cascades, J. Environ. Eng. 113(1): 64-81.

Negm A.M., Abdel-Aal G.M., Habib A.A., Owais T.M., 2003, Effect of end sill in radial basin on characteristics of free hydraulic jumps, Proc. of the 1st Int. Conf. of Civil Engineering Science (ICCESI). Vol. 1, Cairo: p. 12.

Ozkan F., Kaya T., Baylar A., 2009, Study of the influence of venturi weir type on air bubble entrainment, Sci. Res. Essays 4(11): 1184-1193.

Peterka A.J., 1958, Hydraulic design of stilling basin and energy dissipators, Eng. Monograph 25, U.S. Bureau of Reclamation (USBR), Denver, p. 221. 
Rageh O.S., 1999, Effect of baffle blocks on the performance of radial hydraulic jump, Proc. of the 4th International Water Technology Conference (IWTC), Alexandria: 255-269.

Shahmirzadi M., Sumi T., Kantoush S., 2012, The effect of end-sill geometry on functionality of In-ground stilling basin, Annuals Disas. Prev. Res. Inst., Kyoto Univ. 55(2): 561-570.

Tiwari H.L., Gahlot V.K., Tiwari S., 2013, Reduction of scour depth downstream of pipe outlet stilling basin using end sill. Res. J. Eng. Sci. 2(27): 20-25.

Van der Kroon G.T.N., Schram A., 1969, Weir aeration Part I, H2O 22: 528-537.
Wafaie E.M., 2001a, Optimum height for bed sills in stilling basins, Bull. Faculty Eng. Assiut University 29(1): 1-12.

Wafaie E.M., 2001b, Optimum location for bed sills in stilling basins, Bull. Faculty Eng. Assiut University 29(1): 13-24.

Wilhelms S., Gulliver J., Parkhill K., 1992, Reaeration at lowhead hydraulic structures, Tech. Rep. HL-91, US Army Engineer Waterways Experiment Station, Vicksburg, Miss.

Wilson P.C., 2013, Water Quality Notes: Dissolved Oxygen, IFAS Extension Bulletin SL313, Institute of Food and Agricultural Sciences, Uniwersity of Florida, Gainesville, pp. 11. Retrieved from http://edis.ifas.ufl.edu. 